\title{
Ecosystem size predicts social-ecological dynamics
}

\author{
$\underline{\text { Mark A. Kaemingk }}^{1,2}, \underline{\text { Christopher J. Chizinski }}^{2}, \underline{\text { Craig R. Allen }}^{3}$ and Kevin L. Pope $^{3}$
}

\begin{abstract}
Recreational fisheries are complex adaptive systems that are inherently difficult to manage because of heterogeneous user groups (consumptive vs. nonconsumptive) that use patchily distributed resources on the landscape (lakes, rivers, coastlines). There is a need to identify which system components can effectively predict and be used to manage nonlinear and cross-scale dynamics within these systems. We examine how ecosystem size or water body size can be used to explain complicated and elusive angler-resource dynamics in recreational fisheries. Water body size determined angler behavior among 48 Nebraska, U.S.A. water bodies during an 11 year study. Angler behavior was often unique and nonlinear across water body sizes. For example, anglers spent more time fishing and harvested more fish at larger water bodies compared to smaller water bodies. Time fished increased across smaller water bodies, but reached a threshold at larger water bodies. The number of fish released increased as a function of water body size across smaller water bodies and then plateaued. Subtle changes in water body size caused abrupt changes in angler behavior, that is, water body size structures angler-resource dynamics in recreational fisheries. We believe that including water body size, a simple and easily measured metric, in fisheries management will increase effectiveness of cross-scale actions and minimize unintended consequences for recreational fisheries. Applying uniform management actions, e.g., harvest regulations, across small and large water bodies may elicit contrasting anglerresource responses. Water body size may also be useful for understanding angler typologies. Based on our findings, we expect that ecosystem size is a prominent and valuable system component that will determine and explain coupled user-resource dynamics in other complex adaptive systems.
\end{abstract}

Key Words: angler behavior; complex adaptive systems; cross-scale interactions; discontinuity hypothesis; recreational fisheries; socialecological systems

\section{INTRODUCTION}

Humans and natural resources are inextricably linked through nonlinear and cross-scale interactions (Walker et al. 2004). Understanding these complex social-ecological relationships will become increasingly necessary as societies grow and natural resources diminish (Vitousek et al. 1997). How best to detect and manage for abrupt and nonuniform changes within these systems remains a challenge despite advances in theory. Viewing socialecological systems as complex adaptive systems has provided a framework for understanding and characterizing the behavior of system components (Levin et al. 2013, Preiser et al. 2018). Complex adaptive systems are typified by nonlinear and crossscale interactions among system components that can lead to emergent properties (Levin 1998). Failure to account for these emergent properties can be detrimental to system structure and function (Gunderson 2003). Of particular interest is how nonlinear interactions among coupled system components can create positive feedbacks that occur over discrete spatial and temporal scales. The resulting "scale domains" or discrete spatiotemporal scales represent unique relationships that have formed because of discontinuities, i.e., breaks or gaps, among system components, e.g., resources. Identifying these scale domains provides clues for understanding the relationship among system components and how they will react to, and interact with, system disturbances or management actions.

We posit that ecosystem size, an ecological component, could be used to predict social components or behavior within coupled social-ecological systems. Specifically, discontinuities in ecosystem size could shape how human populations interact with natural resources. The size of an ecosystem has been strongly linked to multiple important ecological components (Post et al.
2000, Thompson and Townsend 2005, McHugh et al. 2010). Larger ecosystems, when compared with smaller and similar ecosystem types, often support greater species richness, species diversity, and increased food-chain length (Post et al. 2000). Therefore, discontinuities or gaps in the distribution of ecosystem sizes on the landscape could create unique spatial and temporal processes or scale domains that influence how humans use and interact with ecological resources. Discontinuities in ecological resources could have the ability to structure spatial and temporal processes that lead to responses in social components. Socialecological interactions are inherently complex, but pinpointing where discontinuities exist within an ecosystem-size distribution could unlock the relationship between system components. Developing a cross-scale approach for detecting and predicting scale-dependent social-ecological behavior may lead to more effective management.

Recreational fisheries afford an ideal complex adaptive system to test how discontinuities in ecosystem size could lead to scaledependent and nonlinear human behavior. Water bodies represent discrete ecosystems that vary in size and are patchily distributed across landscapes. Angler populations are heterogeneous and are expected to respond uniquely to water body size (Post et al. 2008, Johnston et al. 2010, Lyach and Čech 2018). From a social perspective, larger water bodies afford better access (e.g., parking areas, boat ramps), amenities (e.g., campgrounds, restaurants), and visibility (e.g., size on the landscape, public advertisement) compared with smaller water bodies (Chizinski et al. 2005). From an ecological perspective, larger water bodies have greater fish species richness and diversity compared with smaller water bodies (Magnuson 1976, Post et al. 2000). Anglers select water bodies that optimize their utility or meet their desires, which largely

${ }^{1}$ Nebraska Cooperative Fish and Wildlife Research Unit, ${ }^{2}$ School of Natural Resources, University of Nebraska, Lincoln, Nebraska, USA, ${ }^{3}$ U.S. Geological Survey, Nebraska Cooperative Fish and Wildlife Research Unit, University of Nebraska, Lincoln, Nebraska, USA 
depends on inherent and coupled social-ecological features (Hunt 2005). Larger water bodies may attract different angler types compared with smaller water bodies, creating unique anglerresource dynamics. Water body size has been used to understand angler behavior, but is often treated as having linear or curvilinear effects, e.g., angler crowding (Johnston et al. 2010, Hunt et al. 2011). The effect of water body size on angler behavior could be discontinuous and responsible for creating distinct angler types or behavior. Current fisheries management approaches do not explicitly account for abrupt and empirical changes that occur across different scales (spatial or temporal). Water body size could therefore reveal hidden cross-scale social-ecological dependencies in recreational fisheries that are currently difficult to track and predict.

Our approach identifies certain social-ecological attributes that are more sensitive to effective cross-scale management. Implementing localized, e.g., water body-level, or regionalized management may have more pronounced effects on certain anglers and associated attributes that are dependent on water body size. In other words, regulating harvest at a few small lakes could lead to unintended consequences among an assemblage of lakes within a region, resulting from an unintended shift in angler pressure and harvest. Herein we highlight how management approaches and policies that incorporate ecosystem size will be most effective and afford long-term resilience and sustainability. We believe that our approach has the ability to predict socialecological dynamics in other complex adaptive systems, e.g., agricultural landscapes, marine protected areas. Specifically, we use an extensive 11-year dataset collected at 48 Nebraska, USA, water bodies to test if and how angler behavior is shaped by water body size. The unresolved question is whether these anglerresource relationships change across (1), water body-size groups, i.e., equal or unequal; or (2), a water body-size gradient, i.e., linear or nonlinear. For example, do we anticipate that anglers spend less time fishing, but harvest more fish at smaller water bodies compared with larger water bodies? Will there be a linear or nonlinear relationship for time spent fishing and for the number of fish harvested across a water body-size gradient?

\section{METHODS}

\section{Study sites}

We accessed the Nebraska Game and Parks Commission water body database and compiled a list of all 618 Nebraska, USA, public water bodies and their respective water body sizes (surface area in ha). Angler information was collected for a subset of 48 public water bodies sampled during 2007-2017 from April through October (Appendix 1: Table A1.1). Water bodies were developed for multiple purposes such as hydropower generation, irrigation storage, flood control, sand-pit mining, and recreational fishing. Fish communities were also diverse and anglers targeted a range of species within and across these water bodies (Pope et al. 2016).

\section{Angler interviews}

Angler surveys were conducted during a single year or multiple years at a water body (mean: 4 years, range: $1-9$ years) across the 48 water bodies sampled. We surveyed anglers onsite at each water body according to previously described methods (Malvestuto et al. 1996, Kaemingk et al.2018). Briefly, our survey design followed a stratified multistage probability sampling regime to determine sampling within each month; monthly sampling was stratified by day type, i.e., week day, weekend day, and by day periods, i.e., morning, afternoon, within each day (Malvestuto 1996). All interviews included in the assessment were completed trips and conducted at the party level where one angler, i.e., the representative of the party, completed the survey. Interview information included the number of anglers in the party, beginning and ending times for fishing, angler type, i.e., boat or bank, U.S. Zone Improvement Plan (zip) code of residence, and the numbers of fish species caught, harvested, and released. From these angler interviews, we extracted 10 variables to represent five party (social) and five catch (social-ecological) attributes of angler behavior. Party attributes reflected social or angler interactions related to individuals travelling together for the purpose of fishing. Catch attributes characterized angler-fish interactions. Each variable was measured at the party level, but ultimately assessed at the water body level, i.e., experimental unit, for subsequent analyses. In other words, we averaged information across all angler parties for each respective water body.

Party variables included party size, time fished, boat anglers, instate anglers, and trip distance. Party size was the number of individuals participating in recreational fishing. Time fished was the duration of recreational fishing for the party, calculated by subtracting beginning time from ending time and reported in decimal hours. Boat anglers represents the proportion of parties intercepted at boat launches, and was coded as a 1 for parties fishing from a boat and a 0 for parties fishing from the bank. Instate anglers represents the proportion of parties that reside in Nebraska, and was coded as 1 for Nebraska residents and 0 for non-Nebraska residents. Trip distance of a party was estimated by the Euclidian distance $(\mathrm{km})$ between the centroid of the residence zip code and the centroid of the water body. Angler zip codes were not collected at all water bodies and thus 23 (of the 48 sampled) water bodies were assessed for proportion of instate anglers and trip distance.

Catch variables included catch richness, fish harvested in catch, fish harvested, fish released, and catch rate. Catch richness described the number of different fish species caught (harvested and released) by a party. Fish harvested in catch was calculated as the number of fish harvested divided by the number of fish caught (harvested plus released) and reported as a percentage. We excluded parties, i.e., missing values, that did not catch any fish for assessments of catch richness and fish harvested in catch. Fish harvested and fish released were the total numbers of fish harvested and fish released, respectively, by a party; zeros were assigned to respective parties that did not harvest or release fish. Catch rate of the party was calculated by dividing the total number of fish caught by time fished.

\section{Discontinuity in water body size}

We used the discontinuity hypothesis to evaluate relationships between water body size and angler behavior. The discontinuity hypothesis was presented as an attractive way to address complicated cross-scale patterns in ecology (Wiens 1989, Holling 1992). Discontinuities or gaps in body size distributions can reveal underlying spatial and temporal processes that are maintained through time within scale domains (Holling 1992, Fisher et al. 2011, Sundstrom et al. 2014). Scale domains are sections of the 
scale spectrum (or range in water body size used here) where patterns and processes are expected to be consistent (Nash et al. 2014). Scale domains are separated by discontinuities or gaps that represent transition zones or a change in the underlying patterns and processes. Unique interactions and opportunities are created for species (or anglers used here) that exist within and across these scale domains. In the same way, identifying discontinuities and scale domains for water body size could highlight unique processes that structure angler behavior and recreational fishery dynamics. We have reason to believe that discontinuous angler types do not respond linearly or in a continuous manner to water body size (Kaemingk et al. 2018). Therefore, this approach provides a meaningful way to (1) quantitatively group water bodies (into their respective scale domains) that adhere to similar patterns and processes and (2) assess how important angler attributes will change across and within these previously identified water body-size groups (referred to as water body groups).

Discontinuities in water body size were examined in the Nebraska public water body dataset using a unimodal null Monte Carlo simulation (Restrepo et al. 1997, Barichievy et al. 2018). Unique water body surface areas, i.e., redundant water body sizes removed from the dataset, were log-transformed and rank-ordered as part of the analysis. This approach allows a continuous unimodal null distribution to be compared with the observed dataset, which is smoothed with a kernel density estimator. The null distribution is then sampled 1000 times and compared with probabilities that the observed discontinuities happened by chance alone, resulting in a Gap Rarity Index (GRI). Significant (alpha =0.05) GRI values therefore tested the null hypothesis that values were drawn from a continuous distribution (Restrepo et al. 1997, Barichievy et al. 2018). Thus, large breaks or gaps in the distribution of water body sizes were indicative of discontinuities in Nebraska public water bodies. These gaps or discontinuities bounded different water body groups for subsequent analyses.

\section{Angler behavior differences among water body groups}

Differences in party and catch attributes were compared among water body groups, i.e., categorical assessment. Party and catch attribute estimates were calculated and summarized for each water body using party-level information. We assessed differences among the water body groups for party and catch attributes using a one-way multivariate analysis of variance (MANOVA). The MANOVA was followed by performing separate one-way ANOVA's and Tukey's HSD (honestly significant difference) tests for each attribute.

\section{Angler behavior relationships among and within water body groups}

Relationships for party and catch attributes were compared among and within water body groups, i.e., continuous assessment. Linear relationships were assessed for each party and catch attribute using an unscaled and a scaled assessment (Allen et al. 2015). The unscaled assessment ignored water body groups whereas the scaled assessment included water body groups as part of the analysis. For the unscaled assessment, we examined attribute relationships across all water body sizes. For the scaled assessment, we examined attribute relationships within each of the water body groups. The strength of each relationship was measured using Pearson's correlation coefficient. Further insight was provided by qualitatively comparing patterns between unscaled and scaled assessments (unscaled: among water body groups, scaled: within water body groups) for each party and catch variable. Variables were transformed $(\ln$ or $\ln +1)$, if necessary, to meet statistical assumptions.

\section{RESULTS}

\section{Discontinuity in water body size}

We identified three major gaps in the size distribution of Nebraska public water bodies $(P<0.05)$, yielding four water body groups (Table 1, Fig. 1). These water body sizes formed groups of extra small, small, medium, and large water bodies. Most water bodies fell within the extra small size group, representing $90 \%$ of all public water bodies in Nebraska. There was a 10-ha gap between the extra small and small water bodies, a 40-ha gap between the small and medium water bodies, and 182-ha gap between the medium and large water body groups.

Table 1. Characteristics for the four water body groups (extra small, small, medium, and large) identified by the discontinuity analysis on water body size (ha). Top portion is all available Nebraska public water bodies and bottom portion is the sampled water bodies.

\begin{tabular}{lccccc}
\hline \hline Water body size & Mean & $\mathrm{N}$ & Min & Median & Max \\
\hline Nebraska public water bodies & & & & & \\
Extra small (XS) & 13.93 & 559 & 0.04 & 3.23 & 104.41 \\
Small (S) & 140.19 & 20 & 114.93 & 139.62 & 182.11 \\
Medium (M) & 323.56 & 22 & 222.58 & 303.51 & 465.39 \\
Large (L) & 2612.34 & 17 & 647.50 & 1151.33 & $12,140.58$ \\
& & & & & \\
Sampled Nebraska public & & & & & \\
water bodies & & & & & \\
Extra small (XS) & 21.29 & 28 & 0.81 & 8.90 & 93.08 \\
Small (S) & 129.70 & 2 & 127.48 & 129.70 & 131.93 \\
Medium (M) & 275.89 & 4 & 257.79 & 273.16 & 299.47 \\
Large (L) & 2891.00 & 14 & 647.50 & 1163.00 & $12,140.58$ \\
\hline
\end{tabular}

Fig. 1. Nebraska public water body size (log transformed) range (end caps) and median values (symbols) representing the four water body groups (XS = extra small, $\mathrm{S}=$ small, $\mathrm{M}=$ medium, $\mathrm{L}=$ large) identified by the discontinuity analysis (see also Table 1).

\begin{tabular}{|c|c|c|c|c|c|c|c|}
\hline & & \multicolumn{2}{|c|}{ XS } & \multicolumn{2}{|l|}{$\mathbf{S} \mathbf{M}$} & $\mathrm{L}$ & \\
\hline-2 & -1 & 0 & 1 & 2 & 3 & 4 & 5 \\
\hline \multicolumn{8}{|c|}{ Water body size (Log ha) } \\
\hline
\end{tabular}

Angler behavior differences among water body groups We interviewed 39,856 parties, representing 85,495 anglers, among all 48 water bodies. Among the water body groups, we interviewed 3652 parties at 28 extra small water bodies, 592 parties at four small water bodies, 4014 parties at two medium water bodies, and 31,598 parties at 14 large water bodies. Differences in party attributes were evident across the water body groups (Table 2, Fig. 2), especially between the two outlying size groups. Party 
Table 2. Multivariate analysis of variance (MANOVA) and univariate analysis for the effect of water body size (extra small, small, medium, and large) on party (top) and catch (bottom) attributes of a regional recreational fishery in Nebraska. Social attributes include party size, time fished, boat anglers, in-state anglers, and trip distance. Catch attributes include catch richness, fish harvested in catch, fish harvested, fish released, and catch rate. Attributes were measured at the party-level but averaged and assessed at the water body level, i.e., experimental unit.

\begin{tabular}{|c|c|c|c|c|c|}
\hline Source & $\begin{array}{c}\text { Wilk's } \\
\lambda\end{array}$ & $\mathrm{df}$ & MS & $F$ & $P$ \\
\hline Party attributes & 0.12 & 15,42 & & 3.28 & $<0.01$ \\
\hline Party size & & 3 & 0.36 & 5.83 & $<0.01$ \\
\hline Error & & 44 & 0.06 & & \\
\hline Time fished & & 3 & 16.27 & 31.39 & $<0.0001$ \\
\hline Error & & 44 & 0.52 & & \\
\hline Boat anglers & & 3 & 0.28 & 12.26 & $<0.0001$ \\
\hline Error & & 44 & 0.02 & & \\
\hline In-state anglers & & 3 & 0.00 & 2.04 & 0.14 \\
\hline Error & & 19 & 0.00 & & \\
\hline Trip distance & & 3 & 3.67 & 7.40 & 0.01 \\
\hline Error & & 19 & 0.50 & & \\
\hline Catch attributes & 0.13 & 15,111 & & 8.17 & $<0.0001$ \\
\hline Catch richness & & 3 & 0.74 & 9.66 & $<0.0001$ \\
\hline Error & & 44 & 0.08 & & \\
\hline Fish harvested in & & 3 & 6.31 & 9.94 & $<0.0001$ \\
\hline catch & & 44 & 0.64 & & \\
\hline \multicolumn{6}{|l|}{ Error } \\
\hline Fish harvested & & 3 & 3.11 & 31.86 & $<0.0001$ \\
\hline Error & & 44 & 0.10 & & \\
\hline Fish released & & 3 & 8.04 & 1.06 & 0.37 \\
\hline Error & & 44 & 7.56 & & \\
\hline Catch rate & & 3 & 2.11 & 2.72 & 0.05 \\
\hline Error & & 44 & 0.77 & & \\
\hline
\end{tabular}

sizes were larger at the large water bodies compared with the extra small water bodies, and parties primarily comprised boat anglers at the large water bodies compared with bank anglers at the extra small water bodies. Anglers at the extra small, small, and medium water bodies spent less time fishing than anglers at the large water bodies. Distance traveled by anglers to the water body also varied with large water bodies attracting anglers from a greater distance than extra small and small water bodies. There was no difference in the proportions of in-state anglers across water body groups (Table 2, Fig. 2).

We also identified differences in catch attributes across the water body groups (Table 2, Fig. 3). Anglers caught more species of fish and harvested more fish at the large water bodies compared with the extra small, small, and medium water bodies. In addition, anglers tended to harvest a greater percentage of their catch at the large and medium water bodies compared with the small water bodies. More fish were also harvested at large water bodies in relation to the extra small water bodies. In contrast, the number of fish released did not differ across water body groups nor did catch rates (Table 2, Fig. 3).
Fig. 2. Party attribute differences $( \pm S E)$ among water body groups (XS = extra small, $\mathrm{S}=$ small, $\mathrm{M}=$ medium, $\mathrm{L}=$ large) for party size, time fished, boat anglers, in-state anglers, and trip distance. Different letters indicate significant differences among water body groups for each attribute as indicated by separate univariate ANOVA's and post-hoc Tukey HSD tests (conversely same letters $=$ no significant difference).

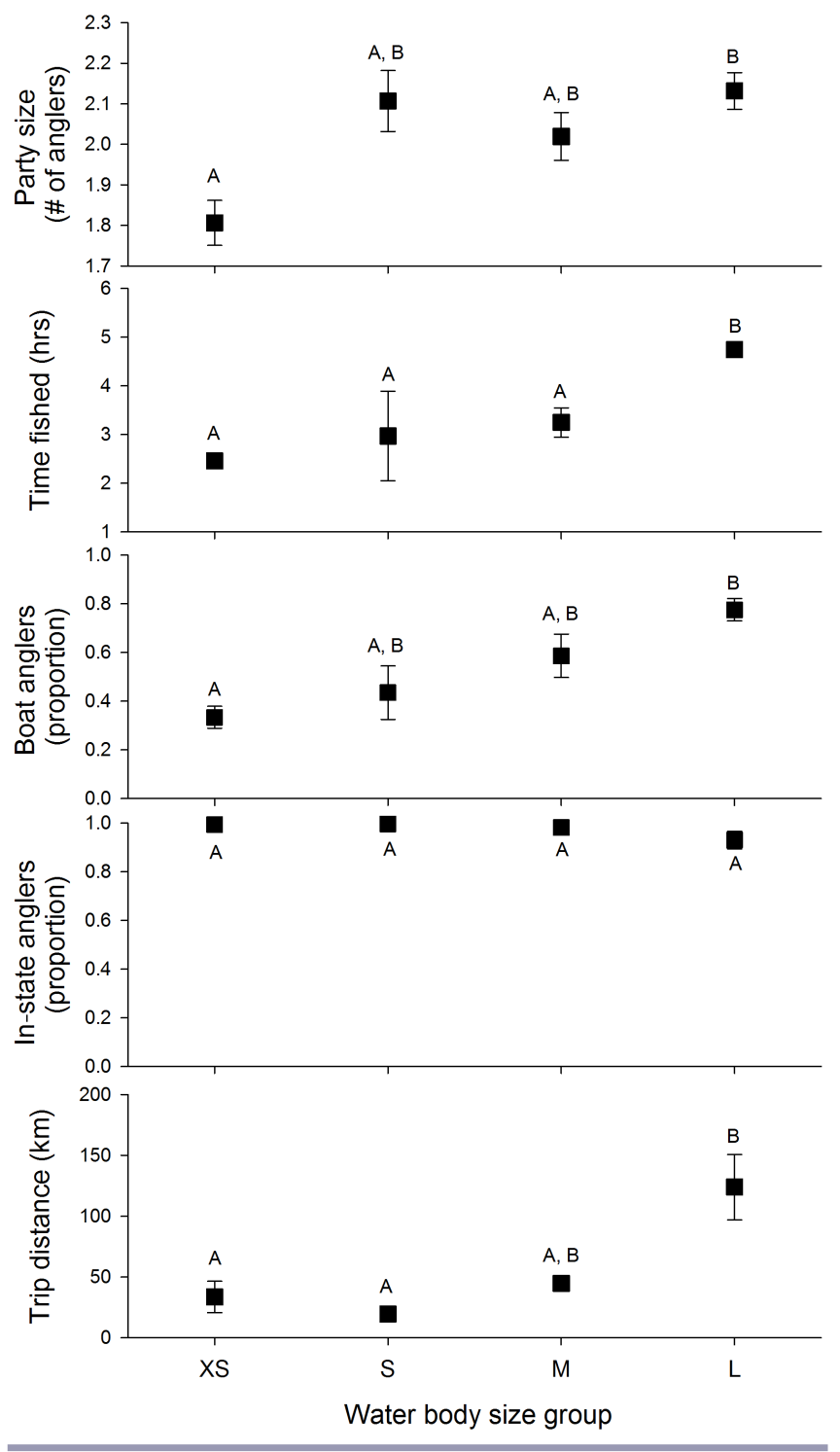

Angler behavior relationships among and within water body groups

We only used the extra small and large water body groups for our scaled assessment because limited sample size prevented examining relationships within the small and medium water body groups. However, the unscaled assessment included all water body groups. All five party attributes were related to water body size in the unscaled assessment that included all water bodies (Table 3, 
Fig. 3. Catch attribute differences $( \pm S E)$ among water body groups (XS = extra small, $\mathrm{S}=$ small, $\mathrm{M}=$ medium, $\mathrm{L}=$ large) for catch richness, fish harvested in catch, fish harvested, fish released, and catch rate. Different letters indicate significant differences among water body groups for each attribute as indicated by separate univariate ANOVA's and post-hoc Tukey HSD tests (conversely same letters $=$ no significant difference).

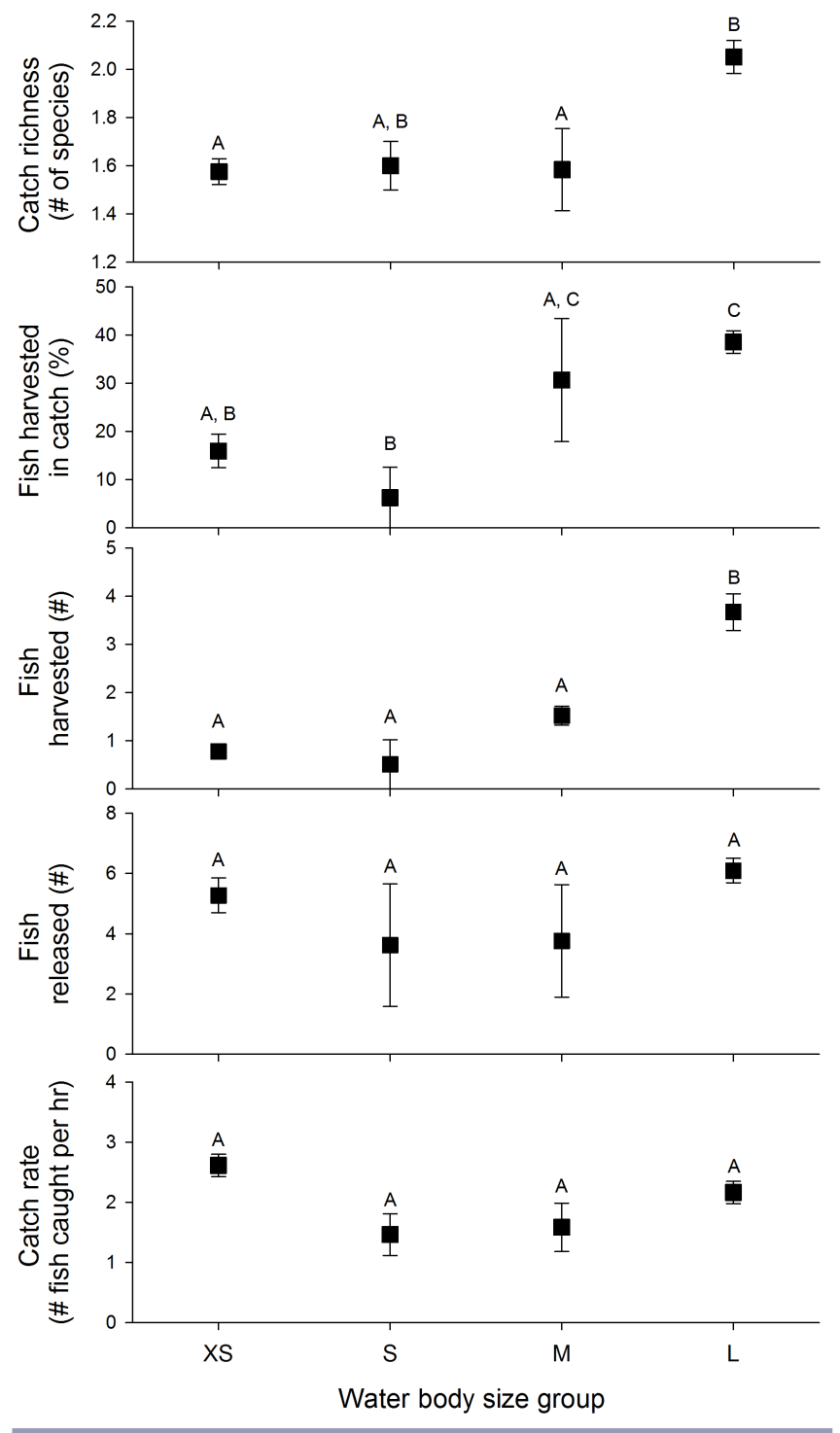

Fig. 4). Party size, time fished, proportion of boat anglers, and trip distance were positively related to water body size whereas the proportion of in-state anglers was negatively related to water body size. Similarly, most ( 3 of 5) party attributes were related to water body size within the extra small water body group (Table 3, Fig. 4). Time fished and the proportion of boat anglers were positively related and trip distance was negatively related to water body size within the extra small water body group. However, no party attributes were related with water body size within the large water body group (Table 3, Fig. 4). There were no consistent
Table 3. Pearson correlation analysis ( $\mathrm{r}$ and $\mathrm{P}$ values) relating water body size for unscaled data (all water bodies) and scaled data (extra small and large water body groups) to party (top) and catch (bottom) attributes of a regional recreational fishery in Nebraska. Party attributes include party size, time fished, boat anglers, in-state anglers, and trip distance. Catch attributes include catch richness, fish harvested in catch, fish harvested, fish released, and catch rate. Significant relationships are indicated with bold font.

\begin{tabular}{|c|c|c|c|c|c|c|}
\hline \multirow[b]{3}{*}{ Attributes } & \multirow{2}{*}{\multicolumn{2}{|c|}{$\begin{array}{l}\text { Unscaled } \\
\text { All }\end{array}$}} & \multicolumn{4}{|c|}{ Scaled } \\
\hline & & & \multicolumn{2}{|c|}{ Extra Small } & \multicolumn{2}{|c|}{ Large } \\
\hline & $r$ & $P$ value & $r$ & $P$ value & $r$ & $P$ value \\
\hline \multicolumn{7}{|l|}{ Party } \\
\hline Party size & 0.56 & $<0.01$ & 0.27 & 0.16 & 0.18 & 0.54 \\
\hline Time fished & 0.87 & $<0.01$ & 0.74 & $<0.01$ & 0.23 & 0.43 \\
\hline Boat anglers & 0.77 & $<0.01$ & 0.58 & $<0.01$ & 0.34 & 0.23 \\
\hline In-state anglers & -0.55 & $<0.01$ & 0.40 & 0.19 & -0.74 & 0.06 \\
\hline Trip distance & 0.52 & 0.01 & -0.66 & 0.02 & 0.53 & 0.22 \\
\hline \multicolumn{7}{|l|}{ Catch } \\
\hline Catch richness & 0.53 & $<0.01$ & 0.14 & 0.46 & -0.31 & 0.28 \\
\hline $\begin{array}{l}\text { Fish harvested in } \\
\text { catch }\end{array}$ & 0.43 & $<0.01$ & -0.22 & 0.27 & 0.23 & 0.42 \\
\hline Fish harvested & 0.66 & $<0.01$ & -0.27 & 0.16 & -0.10 & 0.73 \\
\hline Fish released & 0.17 & 0.25 & 0.38 & 0.04 & -0.40 & 0.16 \\
\hline Catch rate & -0.33 & 0.02 & -0.15 & 0.43 & -0.43 & 0.12 \\
\hline
\end{tabular}

patterns in the party attributes and water body size across the unscaled and scaled assessments.

Most (4 of 5) catch attributes were related to water body size in the unscaled assessment that included all water bodies (Table 3, Fig. 5). Catch richness, the percentage of fish harvested in catch, and the number of fish harvested were positively related and catch rate was negatively related to water body size in the unscaled assessment. Only 1 ( of 5) catch attribute was related to water body size within the extra small water body group; the number of fish released increased as a function of water body size. No catch attributes were related to water body size within the large water body group. There were no consistent patterns in the catch attributes and water body size across the unscaled and scaled assessments.

\section{DISCUSSION}

Angler behavior was related to water body size and was scaledependent (Fig. 6). Identifying discontinuities in water body size was particularly useful for understanding how angler behavior changed as we moved from extra small water bodies to large water bodies. Some social-ecological changes were rather abrupt, e.g., trip distance, whereas others were more gradual, e.g., fish harvested. We interpret these changes and patterns to reflect underlying differences in the spatial and temporal processes structuring these recreational fisheries (Holling 1992). Angler attributes and possibly even anglers appear to respond uniquely to different water body sizes. There were also obvious thresholds across the different water body groups, further indicating inherent scale-domain processes within a water body group that did not extend to other water body groups (Holling 1992). By scaling these 
Fig. 4. Bivariate plots between water body size (Log transformed ha) and party attributes (each dot represents a single water body) across unscaled data (all water bodies) and scaled data (extra small and large water body groups). Water body groups $(\mathrm{XS}=$ extra small, $\mathrm{S}=$ small, $\mathrm{M}=$ medium, $\mathrm{L}=$ large) are listed at top and separated by vertical lines. Party attributes include party size, time fished, boat anglers, in-state anglers, and trip distance. Significant relationships for unscaled data are depicted in the right black sidebar for each plot (positive relationship $=+$, negative relationship $=-$, no relationship $=$ no sign). Significant relationships for scaled data are depicted by trend lines within each plot (no trend line $=$ no relationship).
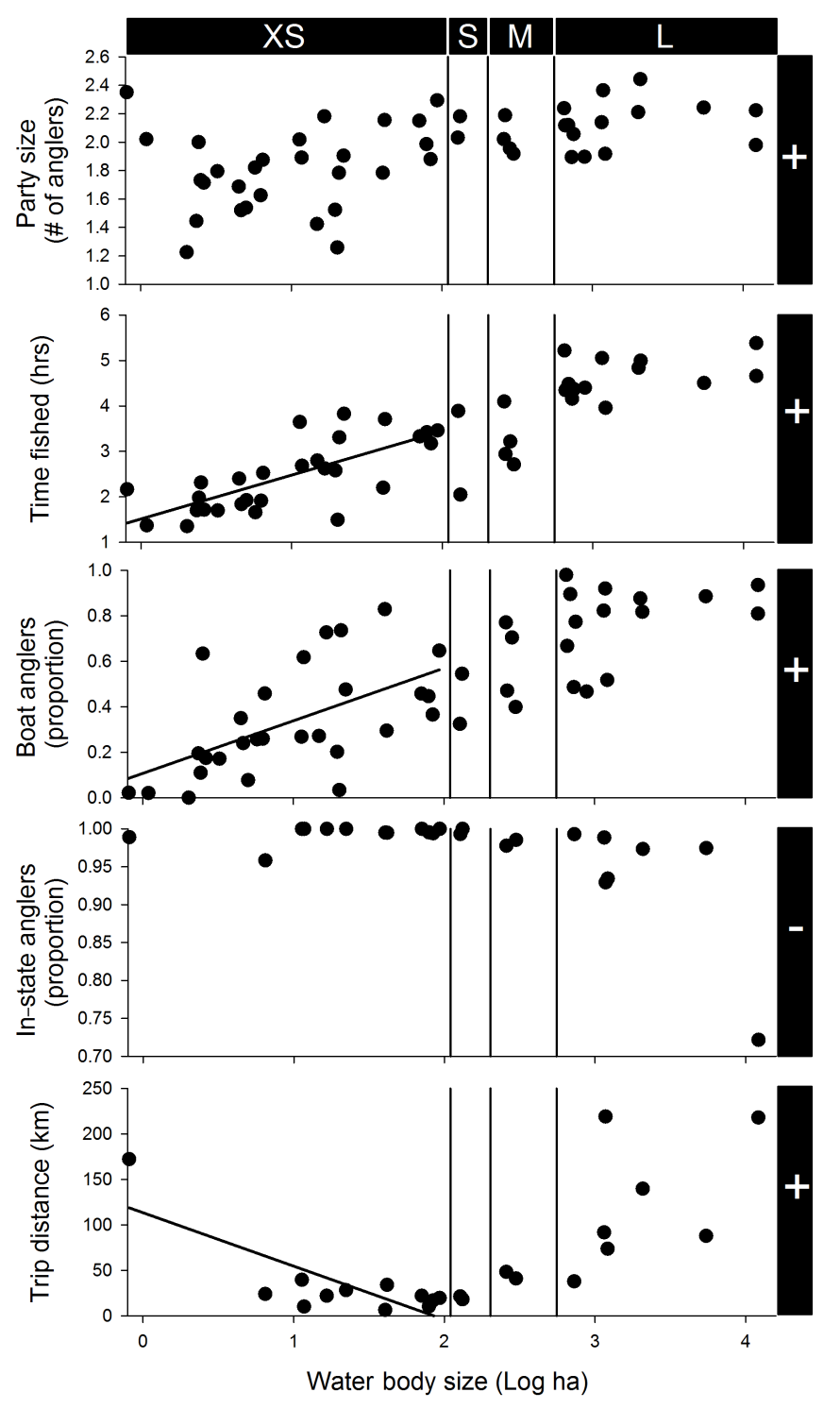

angler dependencies to water body size, we were able to elucidate complex nonlinear patterns in angler behavior that are currently obscured. It is clear that a general or uniform local or regional management approach would not account for these cross-scale
Fig. 5. Bivariate plots between water body size ( $\mathrm{Log}$ transformed ha) and catch attributes (each dot represents a single water body) across unscaled data (all water bodies) and scaled data (extra small and large water body groups). Water body groups (XS = extra small, $\mathrm{S}=$ small, $\mathrm{M}=$ medium, $\mathrm{L}=$ large) are listed at top and separated by vertical lines. Catch attributes include catch richness, fish harvested in catch, fish harvested, fish released, and catch rate. Significant relationships for unscaled data are depicted in the right black sidebar for each plot (positive relationship $=+$, negative relationship $=-$, no relationship $=$ no sign). Significant relationships for scaled data are depicted by trend lines within each plot (no trend line $=$ no relationship).
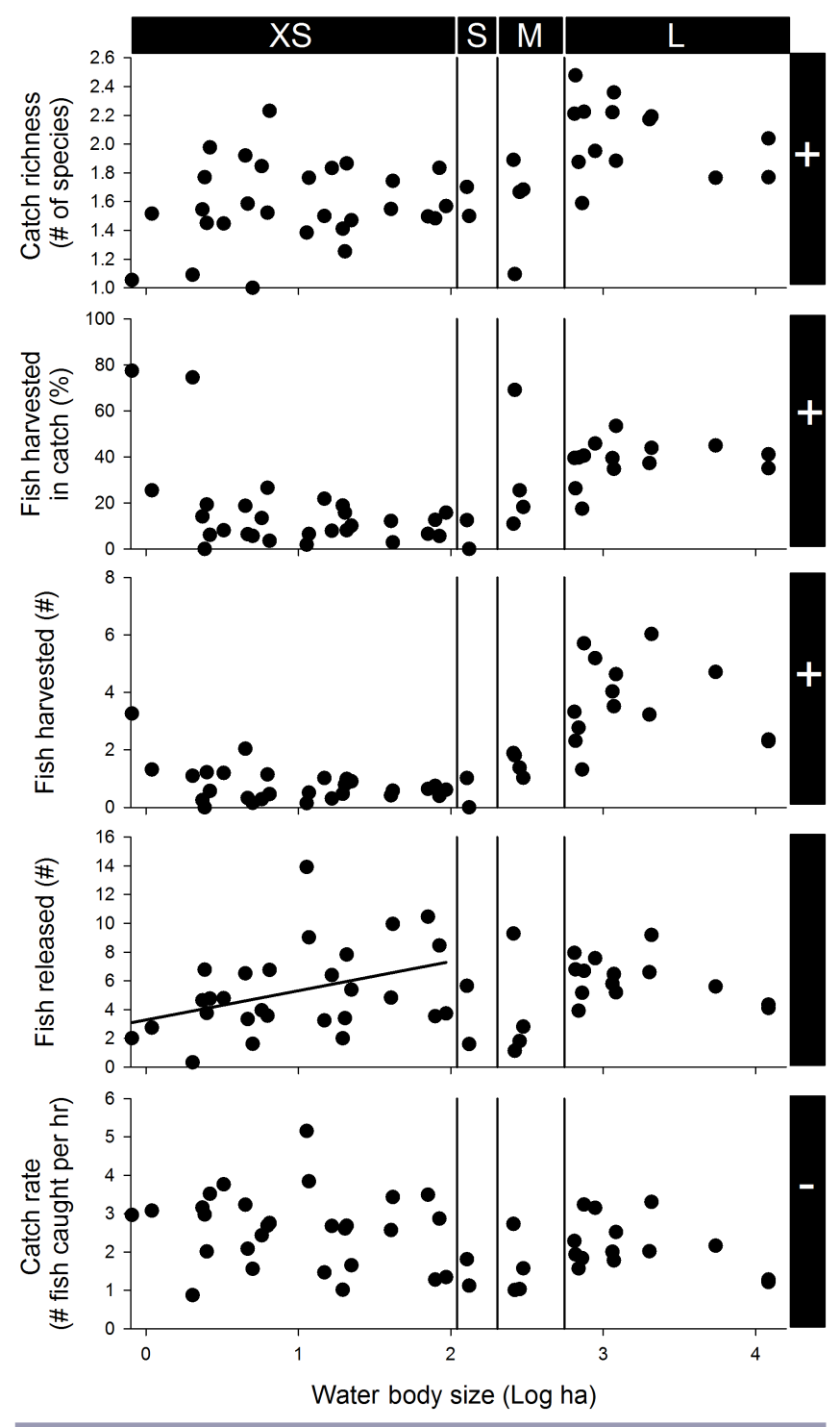

dynamics in angler behavior. Water body size could be used to design management plans and outline how certain socialecological attributes may respond to cross-scale management actions and policies. Currently this information is unavailable, but 
Fig. 6. Conceptual infographic illustrating nonlinear angler behavior responses to water body size. Smaller water bodies are characterized by smaller fishing parties that travel shorter distances and are primarily accessed by bank; anglers at these smaller water bodies also fish for shorter periods of time, harvest fewer fish, and catch fewer species of fish. In contrast, larger water bodies are characterized by larger fishing parties that travel greater distances and are primarily accessed by boat; anglers at these larger water bodies also fish for longer periods of time, harvest more fish, and catch more species of fish.

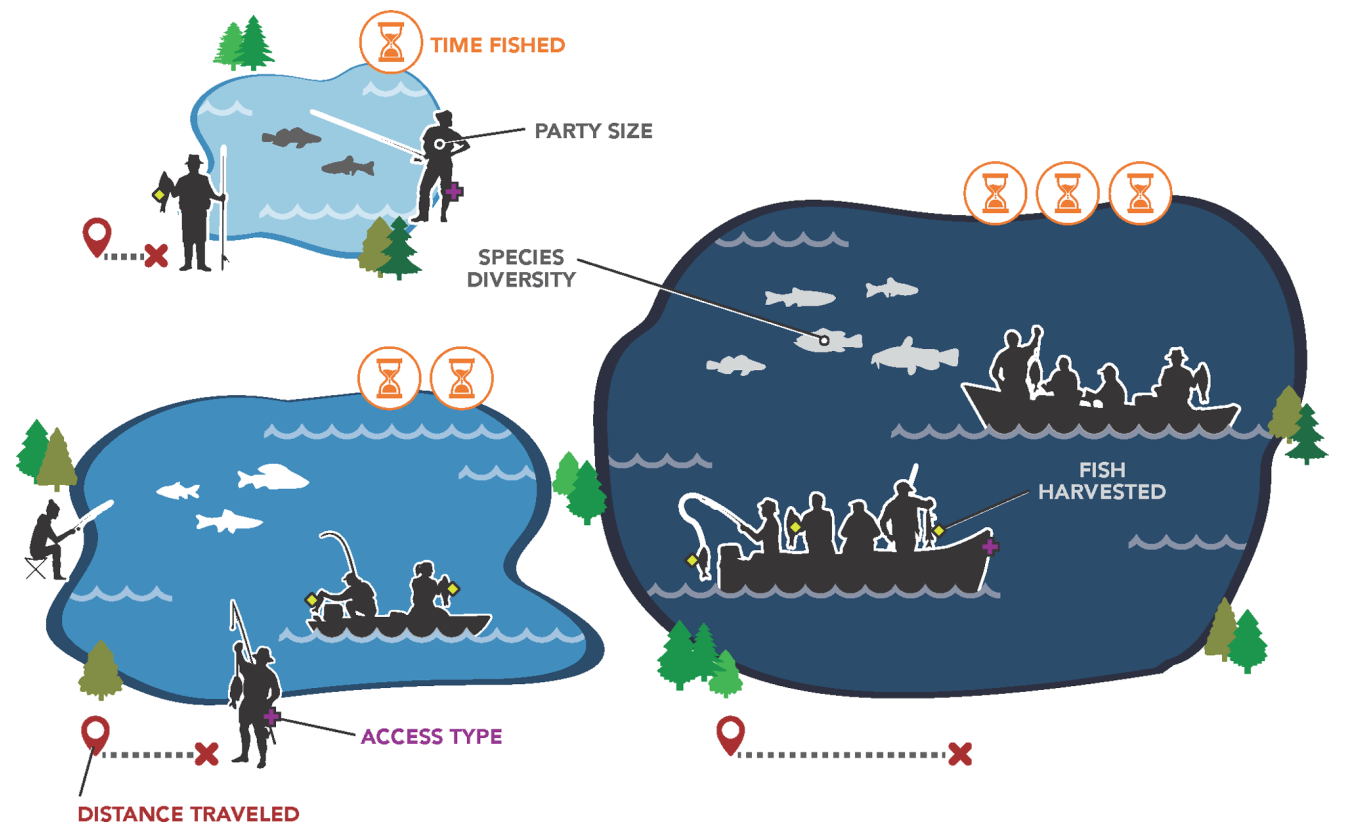

necessary for effective recreational fishery management (Ward et al. 2016, Arlinghaus et al. 2017).

Water body size has proven useful for explaining ecological relationships, ranging from habitat heterogeneity, phytoplankton photosynthesis, fish movement, food-chain length, and species diversity and richness (Magnuson 1976, Fee et al. 1992, Post et al. 2000, Woolnough et al. 2009, Kaemingk et al. 2011). Our study extends this concept to include social-ecological relationships. Previous work identified relationships between the size of fishing grounds and social responses of anglers in the Czech Republic (Lyach and Čech 2018). Water body size appeared to play an important role in the regional synchrony of angler behavior, an emergent property of recreational fisheries (Kaemingk et al. 2018). The sheer number of extra small public water bodies that are patchily distributed in Nebraska ( $90 \%$ of total) could lead to other unique emergent properties in angler behavior. Water body size was also useful for understanding economic values and bipartite networks for angler-fish interactions (Chizinski et al. 2005, 2018). The number of species-targeting angler groups increased with water body size and angler-fish networks were more complex in larger water bodies (Chizinski et al. 2018). We contend that water body size has a strong influence on establishing, maintaining, and supporting angler-resource relationships within recreational fisheries.

The angler-resource interactions we observed among the water body groups generally align with previously described angler specializations or angler types (Chipman and Helfrich 1988,
Fisher 1997, Beardmore et al. 2011). For example, angler-resource interactions at our extra small water bodies are characteristic of low specialization. Less specialized anglers typically fish from a bank, spend less time fishing, and travel shorter distances (Hutt and Bettoli 2007, Beardmore et al. 2011, Ward et al. 2013). In contrast, angler-resource interactions at our large water bodies are characteristic of high specialization. More specialized anglers typically fish from a boat, spend more time fishing, and travel longer distances (Hutt and Bettoli 2007, Beardmore et al. 2011, Ward et al. 2013). Indeed, fish harvest appeared to deviate from these predicted associations between angler types and water body size. We anticipated greater fish harvest in the extra small water bodies, consistent with less specialized anglers (Bryan 1977, Hutt and Bettoli 2007, Lyach and Čech 2018), but found anglers harvested more fish in the large water bodies. In general, water body size may therefore influence how anglers approach fishing at different water bodies or attract different types of anglers altogether, based on motivations and specializations. Discrete water body groups may further be responsible for creating the number of discrete angler types within a given region. Angler utility would then be derived and optimized from existing water body sizes, ultimately leading to complex cross-scale interactions between patchily distributed anglers and water bodies across the landscape (Kaemingk et al. 2018, Matsumura et al. 2019). These intricate angler-water body interactions could explain, in part, our observed scale-dependent angler-resource relationships.

Understanding angler behavior is challenging, but necessary for proper management and conservation (Ward et al. 2016). Angler 
populations are heterogeneous and likely respond uniquely to water body size. Uniform management actions could therefore yield distinct angler responses according to water body size. In some cases, a uniform management action could yield unintended consequences or have no effect at all (Post et al. 2008). For example, adding more boat ramps at smaller water bodies could shift the angler composition from more bank anglers to more boat anglers. A shift in angler composition could then lead to an increase in party size and time spent fishing. Placing more restrictive harvest regulations on larger water bodies may have greater impact on the angler-resource dynamics in these fisheries compared with smaller water bodies (Post et al. 2003). Anglers at smaller water bodies did not harvest as many fish, so placing more restrictive harvest regulations may not have as pronounced effect or even no effect on these fisheries compared with larger water bodies. By considering the importance of water body size in a cross-scale management framework it could ensure greater potential for long-term sustainability and diminish unintended consequences, such as overexploitation (Post et al. 2008), that may emerge from local- to large-scale actions.

Understanding these angler-water body interactions becomes even more valuable if discontinuities in water body size ultimately lead to the creation of discrete angler types. Revealing the number of water body groups or scale domains within a management unit could aid with distinguishing the number of existing angler types, which is critical for fisheries management (Beardmore et al. 2015). We predict that the number of discrete water body groups would be positively correlated with angler-type diversity. Landscapes and management units with a greater number of water body groups should support a larger and more diverse angler population. Developing a management plan for each water body group and associated angler types would be highly beneficial, especially if it accounted for cross-scale interactions among water body groups and angler types. The number of water bodies within each size group may also provide insight to the number of anglers that could be supported. For example, most of Nebraska's public water bodies fall into the extra small water body-size category. We might anticipate that a much larger proportion of Nebraska anglers are attracted to and use these extra small water bodies given their availability (compared with the other three water body groups). It is worth noting that the water bodies we sampled were all artificial and could create unique angler-resource interactions that would deviate from a landscape with natural water bodies. Creation of new reservoirs, closure of existing reservoirs, and even aging of existing reservoirs could increase or decrease the number of angler types and anglers within a population, or even cause a shift in the distribution of anglers among the angler types, i.e., change composition. Creating new reservoirs within current scaledomain gaps, for example between our small and medium water body groups, i.e., 180-220 ha, could potentially even attract and support a new angler type.

We believe that evaluating social-ecological discontinuities in other complex adaptive systems offers great promise for the following: (1), addressing cross-scale interactions; (2), exposing nonlinear dynamics; and (3), highlighting emergent properties (Berkes et al. 2003). For example, social-ecological benefits could be evaluated among size groups of marine protected areas. Discontinuities in the sizes of marine protected areas could expose nonlinear social-ecological relationships that would assist with designing, implementing, and managing these valuable systems (Guidetti and Claudet 2010, Edgar et al. 2014). This approach could also be useful for understanding emergent properties in agricultural-dominated landscapes (Lambin et al. 2000): One could identify discontinuities in the size of farming operations that explain cross-scale interactions in land use, biodiversity, crop and animal production, and income (Donald 2004, Chandler et al. 2013). Our approach to understand complex adaptive systems is attractive because of its simplicity and its ability to detect crossscale changes within these systems, with direct application to management and policy. Adopting this approach could, ultimately, lead to more effective cross-scale management of complex adaptive systems.

Responses to this article can be read online at: http://www.ecologyandsociety.org/issues/responses. php/10961

\section{Acknowledgments:}

We thank T. Anderson, R. Barg, B. Bird, D. Bohnenkamp, Z. Brashears, D. Brundrett, K. Carpenter, M. Cavallaro, P. Chvala, N. Cole, M. Coll, C. Dietrich, L. Dietrich, M. Dedinsky, C. Depue, D. Dobesh, D. Eichner, B. Eifert, H. Evans, A. Fandrich, A. Fedele, R. Foley, R. Fusselman, J. Glenn, A. Glidden, R. Grandi, A. Gray, J. Hair, A. Hanson, B. Harmon, C. Huber, S. Huber, H. Hummel, C. Hothan, J. Johnson, C. Knight, L. Kowalewski, R. Lawing, D. Liess, J. Lorensen, N. Luben, A. Maple, G. Maynard, B. McCue, J. Meirgard, J.P. Montes, C. Nelson, B. Newcomb, C. Niehoff, L. Ohlman, A. Park, A. Pella, M. Petsch, R. Pierson, B. Porter, B. Roberg, P. Rossmeier, C. Ruskamp, J. Rydell, J. Ryschon, T. Sanders, A. Schiltz, J. Schuckman, S. Sidel, M. Smith, J. Spicha, P. Stolberg, D. Thompson, J. Walrath, N. Weaver, and J. Yates for assistance in the field. Special thanks to J. Marohl for creating the conceptual infographic. We thank two anonymous reviewers for substantially improving the manuscript. This project was funded by Federal Aid in Sport Fish Restoration project F-182-R, which was administered by the Nebraska Game and Parks Commission. The Institutional Review Board for the Protection of Human Subjects approved the research protocol (IRB Project ID 14051). Any use of trade, firm, or product names is for descriptive purposes only and does not imply endorsement by the U.S. Government. C. Chizinski was supported by Hatch funds through the Agricultural Research Division at the University of Nebraska-Lincoln and from Federal Aid in Wildlife Restoration project W-120-T-1, administered by the Nebraska Game and Parks Commission. The Nebraska Cooperative Fish and Wildlife Research Unit is jointly supported by a cooperative agreement among the U.S. Geological Survey, the Nebraska Game and Parks Commission, the University of Nebraska, the U.S. Fish and Wildlife Service, and the Wildlife Management Institute. Declarations of interest: none.

\section{LITERATURE CITED}

Allen, C. R., D. G. Angeler, M. P. Moulton, and C. S. Holling. 2015. The importance of scaling for detecting community patterns: success and failure in assemblages of introduced species. Diversity 7(3):229-241. https://doi.org/10.3390/d7030229 
Arlinghaus, R., J. Alós, B. Beardmore, K. Daedlow, M. Dorow, M. Fujitani, D. Hühn, W. Haider, L. M. Hunt, B. M. Johnson, F. Johnston, T. Klefoth, S. Matsumura, C. Monk, T. Pagel, J. R. Post, T. Rapp, C. Riepe, H. Ward, and C. Wolter. 2017. Understanding and managing freshwater recreational fisheries as complex adaptive social-ecological systems. Reviews in Fisheries Science \& Aquaculture 25(1):1-41. https://doi.org/10.1080/23308249.2016.1209160

Barichievy, C., D. G. Angeler, T. Eason, A. S. Garmestani, K. L. Nash, C. A. Stow, S. Sundstrom, and C. R. Allen. 2018. A method to detect discontinuities in census data. Ecology and Evolution 8 (19):9614-9623. https://doi.org/10.1002/ece3.4297

Beardmore, B., W. Haider, L. M. Hunt, and R. Arlinghaus. 2011. The importance of trip context for determining primary angler motivations: are more specialized anglers more catch-oriented than previously believed? North American Journal of Fisheries Management 31(5):861-879. https://doi.org/10.1080/02755947.2$\underline{011.629855}$

Beardmore, B., L. M. Hunt, W. Haider, M. Dorow, and R. Arlinghaus. 2015. Effectively managing angler satisfaction in recreational fisheries requires understanding the fish species and the anglers. Canadian Journal of Fisheries and Aquatic Sciences 72(4):500-513. https://doi.org/10.1139/cjfas-2014-0177

Berkes, F., J. Colding, and C. Folke. 2003. Navigating socialecological systems: building resilience for complexity and change. Cambridge University Press, Cambridge, UK. https://doi. org/10.1017/CBO9780511541957

Bryan, H. 1977. Leisure value systems and recreational specialization: the case of trout fishermen. Journal of Leisure Research 9(3):174-187. https://doi.org/10.1080/00222216.1977.11970328

Chandler, R. B., D. I. King, R. Raudales, R. Trubey, C. Chandler, and V. J. Arce Chávez. 2013. A small-scale land-sparing approach to conserving biological diversity in tropical agricultural landscapes. Conservation Biology 27(4):785-795. https://doi. org/10.1111/cobi.12046

Chipman, B. D., and L. A. Helfrich. 1988. Recreational specializations and motivations of Virginia River anglers. North American Journal of Fisheries Management 8(4):390-398. https:// doi.org/10.1577/1548-8675(1988)008<0390:RSAMOV>2.3.CO;2

Chizinski, C. J., D. R. Martin, D. Shizuka, and K. L. Pope. 2018. Bipartite networks improve understanding of effects of waterbody size and angling method on angler-fish interactions. Canadian Journal of Fisheries and Aquatic Sciences 75(1):72-81. https://doi.org/10.1139/cjfas-2016-0176

Chizinski, C. J., K. L. Pope, D. B. Willis, G. R. Wilde, and E. J. Rossman. 2005. Economic value of angling at a reservoir with low visitation. North American Journal of Fisheries Management 25(1):98-104. https://doi.org/10.1577/M03-102.1

Donald, P. F. 2004. Biodiversity impacts of some agricultural commodity production systems. Conservation Biology 18 (1):17-38. https://doi.org/10.1111/j.1523-1739.2004.01803.x

Edgar, G. J., R. D. Stuart-Smith, T. J. Willis, S. Kininmonth, S. C. Baker, S. Banks, N. S. Barrett, M. A. Becerro, A. T. F. Bernard, J. Berkhout, C. D. Buxton, S. J. Campbell, A. T. Cooper, M. Davey,
S. C. Edgar, G. Försterra, D. E. Galván, A. J. Irigoyen, D. J. Kushner, R. Moura, P. E. Parnell, N. T. Shears, G. Soler, E. M. A. Strain, and R. J. Thomson. 2014. Global conservation outcomes depend on marine protected areas with five key features. Nature 506:216. https://doi.org/10.1038/nature13022

Fee, E. J., J. A. Shearer, E. R. DeBruyn, and E. U. Schindler. 1992. Effects of lake size on phytoplankton photosynthesis. Canadian Journal of Fisheries and Aquatic Sciences 49(12):2445-2459. https://doi.org/10.1139/f92-270

Fisher, J. T., B. Anholt, and J. P. Volpe. 2011. Body mass explains characteristic scales of habitat selection in terrestrial mammals. Ecology and Evolution 1(4):517-528. https://doi.org/10.1002/ ece 3.45

Fisher, M. R. 1997. Segmentation of the angler population by catch preference, participation, and experience: a managementoriented application of recreation specialization. North American Journal of Fisheries Management 17(1):1-10. https://doi. org/10.1577/1548-8675(1997)017<0001:SOTAPB > 2.3.CO;2

Guidetti, P., and J. Claudet. 2010. Comanagement practices enhance fisheries in marine protected areas. Conservation Biology 24(1):312-318. https://doi.org/10.1111/j.1523-1739.2009.01358.X

Gunderson, L. H. 2003. Adaptive dancing: interactions between social resilience and ecological crises. Pages 33-52 in F. Berkes, J. Colding, and C. Folke, editors. Navigating social-ecological systems: building resilience for complexity and change. Cambridge University Press, Cambridge, UK. https://doi.org/10.1017/ CBO9780511541957.005

Holling, C. S. 1992. Cross-scale morphology, geometry, and dynamics of ecosystems. Ecological Monographs 62(4):447-502. https://doi.org/10.2307/2937313

Hunt, L. M. 2005. Recreational fishing site choice models: insights and future opportunities. Human Dimensions of Wildlife 10 (3):153-172. https://doi.org/10.1080/10871200591003409

Hunt, L. M., R. Arlinghaus, N. Lester, and R. Kushneriuk. 2011. The effects of regional angling effort, angler behavior, and harvesting efficiency on landscape patterns of overfishing. Ecological Applications 21(7):2555-2575. https://doi. org/10.1890/10-1237.1

Hutt, C. P., and P. W. Bettoli. 2007. Preferences, specialization, and management attitudes of trout anglers fishing in Tennessee tailwaters. North American Journal of Fisheries Management 27 (4):1257-1267. https://doi.org/10.1577/M05-215.1

Johnston, F. D., R. Arlinghaus, and U. Dieckmann. 2010. Diversity and complexity of angler behaviour drive socially optimal input and output regulations in a bioeconomic recreational-fisheries model. Canadian Journal of Fisheries and Aquatic Sciences 67(9):1507-1531. https://doi.org/10.1139/ $\underline{\mathrm{f10}-046}$

Kaemingk, M. A., C. J. Chizinski, K. L. Hurley, and K. L. Pope. 2018. Synchrony - an emergent property of recreational fisheries. Journal of Applied Ecology 55(6):2986-2996. https://doi. org/10.1111/1365-2664.13164

Kaemingk, M. A., T. L. Galarowicz, J. A. Clevenger, and D. F. Clapp. 2011. Movement of smallmouth bass within the Beaver 
Island Archipelago, northern Lake Michigan. Journal of Great Lakes Research 37(4):625-631. https://doi.org/10.1016/j.jglr.2011.08.005

Lambin, E. F., M. D. A. Rounsevell, and H. J. Geist. 2000. Are agricultural land-use models able to predict changes in land-use intensity? Agriculture, Ecosystems \& Environment 82(1-3):321-331. https://doi.org/10.1016/s0167-8809(00)00235-8

Levin, S. A. 1998. Ecosystems and the biosphere as complex adaptive systems. Ecosystems 1(5):431-436. https://doi. org/10.1007/s100219900037

Levin, S., T. Xepapadeas, A.-S. Crépin, J. Norberg, A. de Zeeuw, C. Folke, T. Hughes, K. Arrow, S. Barrett, G. Daily, P. Ehrlich, N. Kautsky, K.-G. Mäler, S. Polasky, M. Troell, J. R. Vincent, and B. Walker. 2013. Social-ecological systems as complex adaptive systems: modeling and policy implications. Environment and Development Economics 18(2):111-132. https://doi.org/10.1017/ $\underline{\mathrm{S} 1355770 \mathrm{X} 12000460}$

Lyach, R., and M. Čech. 2018. Do recreational fisheries metrics vary on differently sized fishing grounds? Fisheries Management and Ecology 25(5):356-365. https://doi.org/10.1111/fme.12301

Magnuson, J. J. 1976. Managing with exotics-a game of chance. Transactions of the American Fisheries Society 105(1):1-9. https:// doi.org/10.1577/1548-8659(1976)105<1:MWEGOC >2.0.CO;2

Malvestuto, S. P., B. Murphy, and D. Willis. 1996. Sampling the recreational creel. Pages 591-623 in B. R. Murphy amd D. W. Wills, editors. Fisheries techniques. Second edition. American Fisheries Society, Bethesda, Maryland, USA.

Matsumura, S., B. Beardmore, W. Haider, U. Dieckmann, and R. Arlinghaus. 2019. Ecological, angler, and spatial heterogeneity drive social and ecological outcomes in an integrated landscape model of freshwater recreational fisheries. Reviews in Fisheries Science \& Aquaculture 27(2):170-197. https://doi. org/10.1080/23308249.2018.1540549

McHugh, P. A., A. R. McIntosh, and P. G. Jellyman. 2010. Dual influences of ecosystem size and disturbance on food chain length in streams. Ecology Letters 13(7):881-890. https://doi. org/10.1111/j.1461-0248.2010.01484.X

Nash, K. L., C. R. Allen, D. G. Angeler, C. Barichievy, T. Eason, A. S. Garmestani, N. A. J. Graham, D. Granholm, M. Knutson, R. J. Nelson, M. Nyström, C. A. Stow, and S. M. Sundstrom. 2014. Discontinuities, cross-scale patterns, and the organization of ecosystems. Ecology 95(3):654-667. https://doi.org/10.1890/13-1315.1

Pope, K. L., C. J. Chizinski, C. L. Wiley, and D. R. Martin. 2016. Influence of anglers' specializations on catch, harvest, and bycatch of targeted taxa. Fisheries Research 183:128-137. https:// doi.org/10.1016/j.fishres.2016.05.025

Post, D. M., M. L. Pace, and N. G. Hairston. 2000. Ecosystem size determines food-chain length in lakes. Nature 405 (6790):1047-1049. https://doi.org/10.1038/35016565

Post, J. R., C. Mushens, A. Paul, and M. Sullivan. 2003. Assessment of alternative harvest regulations for sustaining recreational fisheries: model development and application to bull trout. North American Journal of Fisheries Management 23 (1):22-34. https://doi.org/10.1577/1548-8675(2003)023<0022:

AOAHRF $>2.0 . \mathrm{CO} ; 2$
Post, J. R., L. Persson, E. A. Parkinson, and T. van Kooten. 2008. Angler numerical response across landscapes and the collapse of freshwater fisheries. Ecological Applications 18(4):1038-1049. https://doi.org/10.1890/07-0465.1

Preiser, R., R. Biggs, A. De Vos, and C. Folke. 2018. Socialecological systems as complex adaptive systems: organizing principles for advancing research methods and approaches. Ecology and Society 23(4). https://doi.org/10.5751/ES-10558-230446

Restrepo, C., L. M. Renjifo, and P. Marples. 1997. Frugivorous birds in fragmented neotropical montane forests: landscape pattern and body mass distribution. Pages 171-189 in W. F. Laurance and R. O. Bierregaard, Jr, editors. Tropical forest remnants: ecology, management and conservation of fragmented communities. University of Chicago Press, Chicago, Illinois, USA.

Sundstrom, S. M., D. G. Angeler, A. S. Garmestani, J. H. García, and C. R. Allen. 2014. Transdisciplinary application of cross-scale resilience. Sustainability 6(10):6925-6948. https://doi.org/10.3390/ $\underline{\text { su6106925 }}$

Thompson, R. M., and C. R. Townsend. 2005. Energy availability, spatial heterogeneity and ecosystem size predict food-web structure in streams. Oikos 108(1):137-148. https://doi. org/10.1111/j.0030-1299.2005.11600.x

Vitousek, P. M., H. A. Mooney, J. Lubchenco, and J. M. Melillo. 1997. Human domination of Earth's ecosystems. Science 277 (5325):494-499. https://doi.org/10.1126/science.277.5325.494

Walker, B., C. S. Holling, S. Carpenter, and A. Kinzig. 2004. Resilience, adaptability and transformability in social-ecological systems. Ecology and society 9(2):5. https://doi.org/10.5751/ ES-00650-090205

Ward, H. G. M., M. S. Allen, E. V. Camp, N. Cole, L. M. Hunt, B. Matthias, J. R. Post, K. Wilson, and R. Arlinghaus. 2016. Understanding and managing social-ecological feedbacks in spatially structured recreational fisheries: the overlooked behavioral dimension. Fisheries 41(9):524-535. https://doi. org/10.1080/03632415.2016.1207632

Ward, H. G. M., M. S. Quinn, and J. R. Post. 2013. Angler characteristics and management implications in a large, multistock, spatially structured recreational fishery. North American Journal of Fisheries Management 33(3):576-584. https:// doi.org/10.1080/02755947.2013.785991

Wiens, J. A. 1989. Spatial scaling in ecology. Functional Ecology 3(4):385-397. https://doi.org/10.2307/2389612

Woolnough, D. A., J. A. Downing, and T. J. Newton. 2009. Fish movement and habitat use depends on water body size and shape. Ecology of Freshwater Fish 18(1):83-91. https://doi.org/10.1111/ j.1600-0633.2008.00326.x 


\section{Appendix 1.}

Table A1.1. Water bodies surveyed and physical characteristics, years surveyed, and the number of angler-parties interviewed.

\begin{tabular}{|c|c|c|c|c|c|}
\hline Waterbody & Latitude $(\mathrm{N})$ & Longitude (W) & $\begin{array}{c}\text { Surface } \\
\text { area (ha) }\end{array}$ & Years surveyed & $\begin{array}{c}\text { Angler } \\
\text { interviews }\end{array}$ \\
\hline Bluestem & $40.626493^{\circ}$ & $-96.794378^{\circ}$ & 132 & 2010,2012 & 22 \\
\hline Box Butte Reservoir & $42.461206^{\circ}$ & $-103.074760^{\circ}$ & 647 & 2012 & 462 \\
\hline Branched Oak Reservoir & $40.981971^{\circ}$ & $-96.855125^{\circ}$ & 728 & 2009-2012, 2014-2016 & 1569 \\
\hline Calamus Reservoir & $41.847825^{\circ}$ & $-99.220833^{\circ}$ & 2,075 & $2009,2011-2017$ & 3688 \\
\hline Conestoga & $40.769101^{\circ}$ & $-96.851692^{\circ}$ & 93 & 2009 & 85 \\
\hline Cottontail & $40.646717^{\circ}$ & $-96.764488^{\circ}$ & 12 & 2010 & 55 \\
\hline Enders Reservoir & $40.437152^{\circ}$ & $-101.538343^{\circ}$ & 691 & $2007-2012$ & 1164 \\
\hline Fremont Lake 1 & $41.449811^{\circ}$ & $-96.561444^{\circ}$ & 5 & $2010-2013$ & 146 \\
\hline Fremont Lake 2 & $41.449891^{\circ}$ & $-96.564159^{\circ}$ & 6 & $2010-2013$ & 278 \\
\hline Fremont Lake 3 & $41.450494^{\circ}$ & $-96.569164^{\circ}$ & 1 & $2010-2013$ & 98 \\
\hline Fremont Lake 4 & $41.450310^{\circ}$ & $-96.574223^{\circ}$ & 2 & $2010-2013$ & 36 \\
\hline Fremont Lake 5 & $41.449296^{\circ}$ & $-96.57258^{\circ}$ & 4 & $2010-2013$ & 163 \\
\hline Fremont Lake 9 & $41.445878^{\circ}$ & $-96.557207^{\circ}$ & 5 & $2010-2013$ & 26 \\
\hline Fremont Lake 10 & $41.443771^{\circ}$ & $-96.550233^{\circ}$ & 15 & $2010-2013$ & 59 \\
\hline Fremont Lake 11 & $41.442613^{\circ}$ & $-96.542336^{\circ}$ & 3 & $2010-2013$ & 63 \\
\hline Fremont Lake 12 & $41.440474^{\circ}$ & $-96.535824^{\circ}$ & 3 & $2010-2013$ & 41 \\
\hline Fremont Lake 15 & $41.439332^{\circ}$ & $-96.538281^{\circ}$ & 20 & $2010-2013$ & 149 \\
\hline Fremont Lake 16 & $41.440828^{\circ}$ & $-96.555104^{\circ}$ & 6 & $2010-2012$ & 39 \\
\hline Fremont Lake 17 & $41.440024^{\circ}$ & $-96.548441^{\circ}$ & 2 & $2010-2013$ & 73 \\
\hline Fremont Lake 18 & $41.438375^{\circ}$ & $-96.539922^{\circ}$ & 3 & $2010-2013$ & 117 \\
\hline Fremont Lake 20 & $41.437707^{\circ}$ & $-96.551542^{\circ}$ & 21 & $2010-2013$ & 550 \\
\hline Gracie Creek Pond & $41.925781^{\circ}$ & $-99.320451^{\circ}$ & 1 & $2012,2014-2017$ & 94 \\
\hline
\end{tabular}




\begin{tabular}{|c|c|c|c|c|c|}
\hline Harlan County Reservoir & $40.057313^{\circ}$ & $-99.272493^{\circ}$ & 5,463 & 2009-2017 & 7631 \\
\hline Holmes Lake & $40.776446^{\circ}$ & $-96.638317^{\circ}$ & 40 & 2009,2011 & 398 \\
\hline Johnson Lake & $40.696404^{\circ}$ & $-99.871988^{\circ}$ & 886 & 2011-2012 & 910 \\
\hline Lake McConaughy & $41.248224^{\circ}$ & $-101.683402^{\circ}$ & 12,141 & 2009-2017 & 3815 \\
\hline Lake Ogallala & $41.213610^{\circ}$ & $-101.666085^{\circ}$ & 263 & 2009-2013 & 397 \\
\hline Lake Wanahoo & $41.234510^{\circ}$ & $-96.614971^{\circ}$ & 268 & 2012-2013, 2016 & 2629 \\
\hline Lewis and Clark Lake & $42.852479^{\circ}$ & $-97.603113^{\circ}$ & 12,141 & 2009-2012 & 2139 \\
\hline Meadowlark & $41.032330^{\circ}$ & $-96.912074^{\circ}$ & 22 & 2012 & 21 \\
\hline Medicine Creek Reservoir & $40.399800^{\circ}$ & $-100.231497^{\circ}$ & 749 & $2007-2012$ & 1099 \\
\hline Merganser & $40.600887^{\circ}$ & $-96.856938^{\circ}$ & 17 & 2010-2011 & 33 \\
\hline Merritt Reservoir & $42.627675^{\circ}$ & $-100.871769^{\circ}$ & 1,176 & $2009-2015$ & 3056 \\
\hline Olive Creek & $40.580063^{\circ}$ & $-96.846971^{\circ}$ & 71 & 2012 & 166 \\
\hline Pawnee & $40.846719^{\circ}$ & $-96.867721^{\circ}$ & 299 & 2009-2010, 2014-2017 & 832 \\
\hline Red Willow Reservoir & $40.358777^{\circ}$ & $-100.671773^{\circ}$ & 659 & $2007-2012$ & 1087 \\
\hline Sherman Reservoir & $41.302863^{\circ}$ & $-98.885985^{\circ}$ & 1,151 & 2009-2011, 2013-2017 & 3026 \\
\hline Skyview Lake & $42.040592^{\circ}$ & $-97.438602^{\circ}$ & 20 & 2010 & 89 \\
\hline Stagecoach & $40.599319^{\circ}$ & $-96.637292^{\circ}$ & 79 & 2009-2010 & 215 \\
\hline Sutherland Reservoir & $41.104676^{\circ}$ & $-101.105632^{\circ}$ & 1,214 & 2016 & 411 \\
\hline Swanson Reservoir & $40.161328^{\circ}$ & $-101.068364^{\circ}$ & 2,013 & $2007-2012$ & 1541 \\
\hline Ta-Ha-Zouka Park Lake & $42.009525^{\circ}$ & $-97.418775^{\circ}$ & 2 & 2010 & 31 \\
\hline Timberpoint & $41.163050^{\circ}$ & $-96.963486^{\circ}$ & 11 & 2009 & 56 \\
\hline Wagon Train & $40.625825^{\circ}$ & $-96.579415^{\circ}$ & 127 & 2011-2012 & 570 \\
\hline Wild Plum & $40.612975^{\circ}$ & $-96.886281^{\circ}$ & 6 & 2011 & 24 \\
\hline Wildwood & $41.037704^{\circ}$ & $-96.838281^{\circ}$ & 42 & $2010-2012$ & 380 \\
\hline Willow Creek Lake & $42.175267^{\circ}$ & $-97.569451^{\circ}$ & 283 & 2010 & 156 \\
\hline Yankee Hill & $40.728949^{\circ}$ & $-96.789979^{\circ}$ & 84 & 2011 & 167 \\
\hline
\end{tabular}

